\title{
Determination of Trace Amount of Iron with as-Triazine Containing Ferroin- Functional Group
}

\author{
Md. Musharraf Hossain ${ }^{1}$, Md. Anwarul Islam ${ }^{2}$, Shahida Begum² and Maksuda Parvin ${ }^{2}$ \\ ${ }^{I}$ Department of Chemistry, Jashore University of Science and Technology, Jashore-7408, Bangladesh \\ ${ }^{2}$ Department of Chemistry, Dhaka University, Dhaka-1000, Bangladesh
}

(Received: 25 April 2019; Accepted: 21 July 2019)

\begin{abstract}
The as-triazines containing iron(II) methine chromophoric group; 3-(2-pyridyl)-5,6-diphenyl-as-triazine (PDT), and 3-(2pyridyl)-5,6-bis( $p$-methoxyphenyl)-as-triazine (PBMPT) have been prepared from commercially available relatively cheaper reagents. The absorptiometric characteristics of the iron(II) complexes with PDT and PBMPT have been reevaluated. The interference of copper ion on the determination of iron with these selective reagents and its masking has also been studied. The application of these spectrophotometric reagents for determination of iron in water samples based on the formation of extractable PDT-iron(II) and PBMPT-iron(II) complexes in chloroform medium has been described. Standard addition technique was used to verify the reliability of the method. Repeated determinations gave results with a very small standard deviation.
\end{abstract}

Keywords: Spectrophotometric, iron determination, ferroin-functional group

\section{Introduction}

The presence of trace amounts of iron in various substances is vital, sometimes objectionable or indicative of contamination or malfunction. The precise determination of this metal ion at ultra-trace levels is of great importance. Iron is one of the most essential micronutrients for human beings. However, it is toxic when its concentration is higher than $0.3 \mathrm{mg} \mathrm{L}^{-1}$. The limit of iron in drinking water is 0.3 $\mathrm{mg} \mathrm{L}^{-1}$ as recommended by WHO.

Colorimetric and atomic absorption methods are generally used for the trace level of iron determination. Colorimetric methods are generally chosen since they require relatively cheaper instrumentation. This method also offers superior sensitivity with appropriate chromogenic reagents. The widely used colorimetric reagents for iron determination is containing $\alpha, \alpha$-diimine structure commonly known as ferroin functional group.

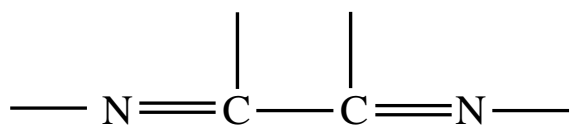

Fritz Blau first reported the synthesis of 2, 2'- bipyridine ${ }^{1}$ and 1,10-phenanthroline $\mathrm{e}^{2}$ and reported their ability to form a red coloured iron(II) salts. The first analytical application of these compounds began in 1930's after long forty years of Blau's findings when Hill ${ }^{3}$, Feigl and Hamburg ${ }^{4}$ simultaneously but independently recommended this compounds for the colorimetric determination of iron(II). Since then many have contributed to extending, modifying and developing uses of 1,10-phenanthroline and related compounds in analytical chemistry. In this regard significant contributions have been made by Smith and $\mathrm{Case}^{5-8}$. The contributions of other workers particularly Schilt ${ }^{9-10}$ are also worthy of mention.

With the hope of developing more sensitive spectrophotometric reagents for the determination of iron(II), Stephen and Islam ${ }^{11}$ have reported some new 3-,
5- and 6-trisubstituted 1,2,4-triazines containing ferroin functional group. The absorptiometric characteristics of the iron(II) complexes of these new as-triazines, solution conditions favourable for chelating and other data are also reported.

It has also been reported that 3-, 5- and 6-trisubstituted 1,2,4-triazines containing ferroin functional group can also be used for the spectrophotometric determination of ruthenium(II) ${ }^{12}$.

Ahmed and Roy ${ }^{13}$ have described a spectrophotometric method for the rapid determination of iron(II) in aqueous solution at trace levels using 2, 3, 4, 5, 7-Pentahydroxyflavone (morin). They have claimed that the method is simple ultrasensitive and highly selective non-extractive method However, this method requires lengthy pretreatment process and aluminum present in the sample may interfere.

Kiran ${ }^{14}$ has described the use of 3-hydroxy benzyl amino benzoic acid as spectrophotometric reagent for the estimation of iron(III) in water samples.

Armila and Subedi ${ }^{15}$ has recently reported the determination of total iron in rice and maize spectrophotometrically by using 1,10-phenanthroline as colour forming reagent.

Ahmed et $a l^{16}$ has recently reported a method for the determination of iron in various samples including some environmental water samples.

Since the compounds containing ferroin functional group are highly selective and widely used for iron determination, in this study two highly sensitive and selective iron(II) reagents; 3-(2-pyridyl)-5,6-diphenyl-as-triazine (PDT), and 3-(2-pyridyl)-5,6-bis(p-methoxyphenyl)-1,2,4-triazine (PBMPT) $^{11}$ were prepared from commercially available relatively cheaper reactants and their application for the trace level estimation of iron(II) in water samples of different sources such as tap water, pond water and river water. Iron(II) contents in different water samples were determined 
using solvent extraction method. The absorptiometric characteristics of the iron(II) complexes of these as-triazine reagents have also been re-evaluated.

\section{Experimental}

Preparation of benzoin, anisoin and their conversion to benzil and anisil

These compounds were prepared from benzaldehyde and anisaldehyde following the method described in Vogel's text book of practical organic chemistry ${ }^{17}$.

\section{Preparation of pyridyl-2-hydrazidine}

In this study this compound was prepared following the method of Stephen and Islam ${ }^{11}$. A mixture of $13.2 \mathrm{~g}(0.127$ mol) of 2-cyanopyridine, $25-\mathrm{mL}$ of ethanol and $68-\mathrm{mL}$ of $80 \%$ hydrazine hydrate was stirred for 2 hours. This was diluted with an equal volume of distilled water and extracted with dichloromethane. The dichloromethane extract was dried with anhydrous $\mathrm{Na}_{2} \mathrm{SO}_{4}$. The solvent was completely removed by rotary evaporator. The residue was recrystallised from hot toluene solution. $10.6 \mathrm{~g}$ (yield, 62\%) of white crystalline product of pyridyl-2-hydrazidine were obtained, m.p $92-94^{\circ} \mathrm{C}$.

\section{Preparation of 3-(2-pyridyl)-5,6-diphenyl-1,2,4-triazine (PDT)}

This compound was prepared by the method of Stephen and Islam $^{11}$. 0.017 moles of benzil and 0.017 moles of pyridyl2-hydrazidine were dissolved in $60-\mathrm{mL}$ of ethanol and heated under reflux for 10 minutes and allowed to stand overnight. The resulting precipitates were collected by filtration, washed with a little hexane and air dried. The crude materials were recrystallised from ethanol to produce $4.18 \mathrm{~g}(67 \%)$ of yellow crystals, m.p. $186-188^{\circ} \mathrm{C}$.

Preparation of 3-(2-pyridyl)-5,6-bis(p-methoxyphenyl)-1, 2,4-triazine (PBMPT)

This compound was also prepared according to the method of Stephen and Islam ${ }^{11}$. Mixture of 4,4'-dimethoxybenzil $(0.017 \mathrm{~mol})$ and pyridyl-2-hydrazidine $(0.017 \mathrm{~mol})$ were taken in $80-\mathrm{mL}$ of ethanol and refluxed for 15 minutes. The volume of the solution was reduced to one third under reduced pressure. The yellow material was filtered off, air dried and recrystallized from ethanol to give $4.30 \mathrm{~g}(53 \%)$ of highly crystalline yellow product, m.p $152-154{ }^{\circ} \mathrm{C}$.

\section{Reagents}

\section{Stock iron(II) solution}

A standard stock iron(II) solution was prepared by dissolving required amount of analaR grade Mohr's salt in small volume of distilled water and $10-\mathrm{mL}$ concentrated $\mathrm{H}_{2} \mathrm{SO}_{4}$ was added before dilution to $1-\mathrm{L}$ with distilled water. The solution of working concentration was prepared by dilution of the standard solution.

\section{Stock $C u(I I)$ solution}

A working standard $\mathrm{Cu}(\mathrm{II})$ solution (100 $\mathrm{mg} \mathrm{L}^{-1}$ ) was prepared by dissolving required amount of analaR grade $\mathrm{CuCl}_{2} \cdot 2 \mathrm{H}_{2} \mathrm{O}$ in a $100-\mathrm{mL}$ volumetric flask. 1-2 drops of concentrated hydrochloric acid was added and diluted up to the mark with distilled water.

\section{Organic reagent solutions}

$0.005 \mathrm{M}$ PDT and PBMPT solutions were prepared by dissolving required amounts in ethanol. The stock solution was diluted to prepare working concentration of the reagent for spectrophotometric examinations.

\section{Buffer solution}

Buffer solutions formally 1 molar in strength at unit $\mathrm{pH}$ intervals in the range 1-11 were prepared containing, where appropriate, one or more of the following analytical grade chemicals: hydrochloric acid, acetic acid, potassium chloride, sodium acetate, ammonium acetate, ammonium chloride and aqueous ammonia solution.

\section{Reducing agent}

$10 \mathrm{~g}$ of hydroxylamine hydrochloride was dissolved in 90$\mathrm{mL}$ of distilled water to prepare a $10 \%(\mathrm{w} / \mathrm{v})$ solution.

\section{Iron free buffer solution ( $\mathrm{pH}-4.76)$}

Acetate buffer solution of $\mathrm{pH} 4.76$ was prepared in a 250 $\mathrm{mL}$ volumetric flask. $100-\mathrm{mL}$ buffer solution was transferred into a $250-\mathrm{mL}$ separatory funnel. $2-\mathrm{mL}$ of $10 \%$ reducing agent, $5-\mathrm{mL}$ of organic reagent solution and $10-15-\mathrm{mL}$ of chloroform were added in turn. The mixture was shaken thoroughly and allowed to stand. After separation of two layers, the organic layer was discarded and the aqueous layer was collected as iron free buffer solution.

\section{Iron free reducing agent solution}

About $100-\mathrm{mL}$ of the reducing agent solution was taken in a 250-mL separatory funnel followed by addition of 5-mL of organic reagent solution, 5-mL buffer solution of $\mathrm{pH} 4.76$ and $10-\mathrm{mL}$ chloroform. This mixture was shaken thoroughly and allowed to stand for the separation of two layers. The aqueous layer was collected for using as iron free reducing agent solution.

\section{Apparatus}

A double beam UV-Visible (Model: UV/Vis-1800) Spectrophotometer, SHIMADZU, Japan, a digital $\mathrm{pH}$ meter Mi 151, pH/ORP/Temperature Bench Meter, U.S.A, a melting point meter KRUSS were used in this research work.

\section{Analytical procedure}

\section{Complex formation study}

To each of a series of $25-\mathrm{mL}$ volumetric flask; $5.0-\mathrm{mL}$ of standard iron(II), 2-mL of $10 \%$ hydroxylamine hydrochloride solution, $5-\mathrm{mL}$ of the particular organic reagents and $5-\mathrm{mL}$ of 
buffer (different in each flask and covering the $\mathrm{pH}$ range 111) and then diluted to volume with ethanol. The colour formation indicated the $\mathrm{pH}$ range over which complexation occurred. This was carried out with both of the reagents separately and the results are given in Table 1.

Table 1. Formation conditions and colour of the iron(II) complexes at different $\mathrm{pH}$

\begin{tabular}{|c|c|c|c|c|c|}
\hline \multirow{2}{*}{$\begin{array}{l}\text { Organic } \\
\text { reagent }\end{array}$} & \multirow{2}{*}{$\begin{array}{l}\text { Colour of } \\
\text { complex }\end{array}$} & \multirow{2}{*}{$\begin{array}{c}\text { Time of } \\
\text { development }\end{array}$} & \multicolumn{2}{|c|}{$\mathrm{pH}$ ranges for } & \multirow{2}{*}{$\begin{array}{c}\text { Working } \\
\mathrm{pH} \text { for data }\end{array}$} \\
\hline & & & $\begin{array}{l}\text { Colour } \\
\text { formation }\end{array}$ & $\begin{array}{l}\text { Maximum } \\
\text { colour } \\
\text { formation }\end{array}$ & \\
\hline PDT & Magenta & Immediate & $1-8$ & $3-8$ & 4.76 \\
\hline PBMPT & Violet & Immediate & $1-11$ & $2-8$ & 4.76 \\
\hline
\end{tabular}

Recommended procedure for spectrophotometric study

The colour of the complex was developed as described above with buffer solution of $\mathrm{pH} 4.76$ for measurement in aqueous ethanol medium. For measurements in chloroform media colour of the complex was developed according to following procedure;

Standard iron(II) working solution of different volume was transferred into a $250-\mathrm{mL}$ separatory funnel. $2-\mathrm{mL}$ of $10 \%$ hydroxylamine hydrochloride, 5-mL of organic reagent solution, 5-mL of buffer solution of $\mathrm{pH} 4.76$ were added in turn into the separatory funnel followed by $8-10-\mathrm{mL}$ of chloroform. The contents of the funnel were mixed well and allowed to settle. The organic layer was collected in a 25 $\mathrm{mL}$ volumetric flask and the extraction was repeated with a further $8-10-\mathrm{mL}$ of chloroform. 1-2-mL of ethanol was added to the flask before dilution to volume with chloroform.

\section{Sensitivity determination}

A series of metal complex solutions varying the concentration of iron(II) were prepared following the recommended procedure both in aqueous ethanol and chloroform media. Absorbances of the solutions were recorded at $\lambda_{\max }$ against the similarly, prepared reagent blank solution. The absorbances were plotted against corresponding concentrations of iron(II). Molar absorptivity (c) at $\lambda_{\max }$ was calculated from the linear regression coefficient. The results are given in the following table (Table 2).

Table 2. Absorption Characteristics of iron(II) complexes of PDT and PBMPT

\begin{tabular}{|c|c|c|c|c|}
\hline \multirow{2}{*}{$\begin{array}{c}\text { Organic } \\
\text { reagent }\end{array}$} & \multicolumn{2}{|c|}{ Aqueous-ethanol } & \multicolumn{2}{c|}{ Chloroform } \\
\cline { 2 - 5 } & $\lambda_{\max }(\mathrm{nm})$ & $\begin{array}{c}\varepsilon \\
\left(\mathrm{L} \mathrm{mol}^{-1} \mathrm{~cm}^{-}\right. \\
1\end{array}$ & $\begin{array}{c}\lambda_{\max } \\
(\mathrm{nm})\end{array}$ & $\begin{array}{c}\varepsilon \\
\left(\mathrm{L} \mathrm{mol}^{-1}\right. \\
\left.\mathrm{cm}^{-1}\right)\end{array}$ \\
\hline PDT & 556.0 & 24,000 & 556.0 & 24,150 \\
\hline PBMPT & 561.0 & 31,100 & 560.0 & 31,300 \\
\hline
\end{tabular}

Study of interferences of $\mathrm{Cu}$ ions and their masking during the determination of iron with PDT and PBMPT

The interference of copper ions and their masking have been studied by the following procedure.
Exactly same volume of standard iron(II) solution was taken to a series of $25-\mathrm{mL}$ volumetric flasks. This was followed by the addition of varying amount of standard copper(II) solution containing zero to twenty times of the amount of iron taken. Following recommended procedure the colours of the metal complexes with the both astriazines were developed. Absorbances of the solutions were recorded against the similarly prepared reagent blank solution at the wavelength of maximum absorbance $\left(\lambda_{\max }\right)$.

In this series of solutions about 5-10 mg of thiourea were added, shaken and allowed to stand for five minutes. Absorbances of this series of solutions were again recorded against reagent blank solution.

\section{Determination of iron(II) in different water samples}

The suspended impurities of water samples collected from different sources were removed by filtration through a sintered glass crucible (porosity 4).

\section{Preparation of calibration curve}

Standard iron(II) working solution of different volume was transferred into a $250-\mathrm{mL}$ separatory funnel. $2-\mathrm{mL}$ of $10 \%$ (w/v, iron and copper free) hydroxylamine hydrochloride, 5-mL of organic reagent solution, 5-mL of iron free buffer solution of $\mathrm{pH} 4.76$ were added in turn into the separatory funnel followed by $8-10-\mathrm{mL}$ of chloroform. The contents of the funnel were mixed well and allowed to settle. The organic layer was collected in a $25-\mathrm{mL}$ volumetric flask. The extraction procedure was repeated with further 7-8-mL of chloroform. 1-2-mL of ethanol and about 10-15 $\mathrm{mg}$ of thiourea were added to the flask before dilution to volume with chloroform. The absorbances were measured at $\lambda_{\max }$ against the similarly prepared reagent blank solution. Absorbances of the solutions were plotted against the concentration of iron(II) to prepare the calibration curve. This calibration curve is used to estimate iron(II) contents in the supplied water samples.

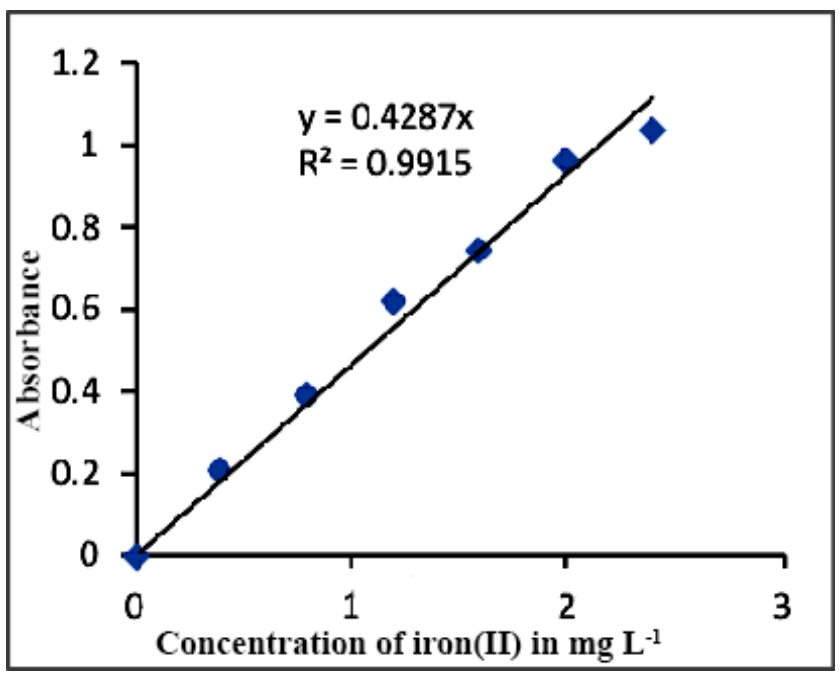

Fig. 1. Calibration curve for iron(II) complex of PDT in chloroform medium 


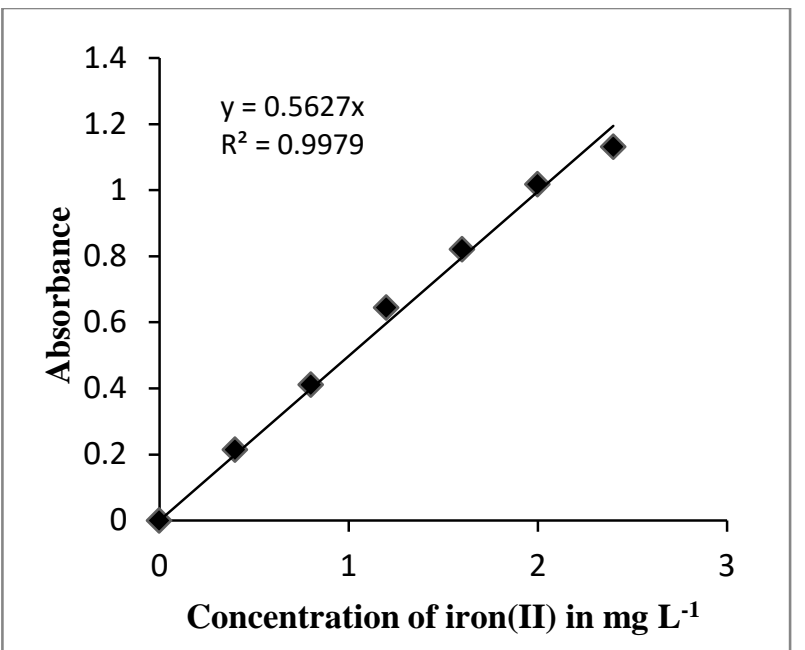

Fig. 2. Calibration curve for iron(II) complex of PBMPT in chloroform medium

\section{Determination of iron in water samples}

A measured aliquot $(25-50-\mathrm{mL})$ of the water sample was taken into a $250-\mathrm{mL}$ separatory funnel. $10 \%$ (iron free) hydroxylamine hydrochloride $(2-\mathrm{mL})$, organic reagent $(5$ $\mathrm{mL})$, iron free buffer of $\mathrm{pH} 4.76(5-\mathrm{mL})$, and $8-10-\mathrm{mL}$ of chloroform were added into the separatory funnel. The mixture was shaken well and allowed to stand. The chloroform layer was collected into a $25-\mathrm{mL}$ calibrated flask. The extraction was repeated with further amount of chloroform. 1-2-mL of ethanol and about 10-15 $\mathrm{mg}$ of thiourea were also added to the flask before dilution to volume with chloroform. The absorbance of the solution was measured at $\lambda_{\max }$ against the reagent blank and the iron content of the water sample was calculated from the calibration curve. At least five to six separate determinations were carried out with each water sample. This process was repeated with the water sample with the addition of known amount of iron.

\section{Results and Discussion}

The melting point of the as-triazines; 3-(2-pyridyl)-5,6diphenyl-as-triazine (PDT) and 3-(2-pyridyl)-5,6-bis( $p$ methoxyphenyl)-as-triazine (PBMPT) prepared in this investigation are in agreement with the reported values confirming the purity of the compound.

The highly intense magenta colour of iron(II)-PDT and violet colour of iron(II)-PBMPT were found to be developed immediately over a $\mathrm{pH}$ range of 2-8. The visible absorption spectrum of the iron(II) complexes of PDT and PBMPT show a single absorption peak at 556 and $562 \mathrm{~nm}$ with the molar absorptivity of $2.4 \times 10^{4} \mathrm{~L} \mathrm{~mol}^{-1} \mathrm{~cm}^{-1}$ and $3.11 \times 10^{4} \mathrm{~L}$ $\mathrm{mol}^{-1} \mathrm{~cm}^{-1}$ respectively. It appeared that both PDT and PBMPT iron(II) complexes followed Beer's law over the experimental concentration range of $0.00-2.40 \mathrm{mg} \mathrm{L}^{-1}$. Stephen and Islam ${ }^{11}$ have also reported that the iron(II)-PDT complex gave a single absorption peak at $555 \mathrm{~nm}$ with molar absorptivity of $2.44 \times 10^{4} \mathrm{~L} \mathrm{~mol}^{-1} \mathrm{~cm}^{-1}$. On the other hand two absorption peaks at 562 and $405 \mathrm{~nm}$ with the values of molar absorptivity $3.25 \times 10^{4}$ and $2.0 \times 10^{4} \mathrm{~L} \mathrm{~mol}^{-1} \mathrm{~cm}^{-1}$ respectively for the iron(II)-PBMPT complex have been reported. Slight variation in the wavelength of maximum absorbance $\left(\lambda_{\max }\right)$ may be due instrumental and experimental error. A bit lower molar absorptivity value for the PBMPT iron(II) complex found in this investigation may be due to use of analaR grade Mohr's salt instead of using electrolytic iron. The disappearance of the reported peak at $405 \mathrm{~nm}$ for the iron(II)-PBMPT complex is not clear. This may be due variation in the instrument.

Both reagents and their iron(II) complexes are highly soluble in aqueous-ethanol medium. It is observed that PBMPT is far more sensitive than commonly used $\mathrm{PDT}^{9}$ and 1,10-phenanthroline ${ }^{2}$.

PBMPT appears to be an attractive alternative for the spectrophotometric determination of iron(II) in various situations due to its higher sensitivity and easier way of preparation from commercially available relatively cheaper reactants.

The study of the interferences of copper ions and its masking revealed that copper ion interferes; however, this interference can be entirely eliminated by the addition of thiourea.

In this study trace amount of iron in different water samples were determined based on the extraction of iron(II) complexes of PDT and PBMPT in chloroform.

Different water samples were analyzed in multiple times using both PDT and PBMPT and the results are given in Table 3 - 4.

Table 3. Iron content of water samples determined by PDT

\begin{tabular}{|c|c|c|}
\hline $\begin{array}{c}\text { Sources of } \\
\text { Water sample }\end{array}$ & $\begin{array}{c}\text { Mean of the iron } \\
\text { found } \times 10^{2} \mathrm{mg} \mathrm{L}^{-} \\
1\end{array}$ & $\begin{array}{c}\text { Std. deviation of the } \\
\text { iron found } \times 10^{2} \\
\mathrm{mg} \mathrm{L}^{-1}\end{array}$ \\
\hline $\begin{array}{c}\text { Tap water } \\
\text { (Dhaka } \\
\text { University) }\end{array}$ & 4.112 & \pm 0.267 \\
\hline $\begin{array}{c}\text { Pond water } \\
\text { (Shahidullah } \\
\text { Hall, DU) }\end{array}$ & 6.168 & \pm 0.266 \\
\hline $\begin{array}{c}\text { River water } \\
\text { Hazaribagh, } \\
\text { Buriganga, } \\
\text { Dhaka) }\end{array}$ & 24.205 & \pm 0.266 \\
\hline
\end{tabular}

Table 4. Iron content of water samples determined by PBMPT

\begin{tabular}{|c|c|c|}
\hline $\begin{array}{c}\text { Sources of } \\
\text { Water sample }\end{array}$ & $\begin{array}{c}\text { Mean of the } \\
\text { iron found } \times 10^{2} \\
\mathrm{mg} \mathrm{L}^{-1}\end{array}$ & $\begin{array}{c}\text { Std. deviation of the } \\
\text { iron found } \times 10^{2} \\
\mathrm{mg} \mathrm{L}^{-1}\end{array}$ \\
\hline $\begin{array}{c}\text { Tap water } \\
\text { (Dhaka } \\
\text { University) }\end{array}$ & 4.998 & \pm 0.199 \\
\hline $\begin{array}{c}\text { Pond water } \\
\text { (Shahidullah } \\
\text { Hall, DU) }\end{array}$ & 7.045 & \pm 0.203 \\
\hline $\begin{array}{c}\text { River water } \\
\text { (Hazaribagh, } \\
\text { Buriganga, } \\
\text { Dhaka) }\end{array}$ & 28.897 & \pm 0.202 \\
\hline
\end{tabular}


Quantitative recovery of iron was confirmed by the standard addition method. Multiple determinations of trace amount of iron in water samples proved successful, yielding results with a very small standard deviation.

\section{References}

1. Blau, F. 1888. The distillation of Pyridine Monocarboxylic Acid Salts. Chem. Ber. 21, 1077-1078.

2. Blau, F. 1898. About New Organic Metal Compounds. Monatshefte for chemistry and related parts of other sciences, 19 (1), 647-689.

3. Hill, R. 1931. A Method for the Estimation of Iron in Biological Material. Proc. Roy. Soc. of London, Series B, 107, 205-214. Chem. Abstracts., 25, 2387.

4. Feigl, F. and H. Hamburg, 1931. Contributions to the Detection of Iron. Z. Anal. Chem, 86(1), 7-13; 1932. Colorimetric determination of iron with 2,2'-bipyridine ibid., 93, 199-202.

5. Smith, G. F. and F. P. Richter, 1944. Phenanthroline and Substituted Phenanthroline Indicators. G. F. Smith Chemical Co., Columbus, Ohio. 27-39.

6. Case, F. H, 1960. A Review Synthesis of Organic Compounds Containing the Ferroin Group. G. F. Smith Chemical Co., Columbus, Ohio. 5-36.

7. Diehl, H., G. F. Smith, L. McBride and R. Cryberg, 1965. The Iron Reagents; Bathophenanthroline, Bathophenanthroline disulphonic acid, 2,4,6- Tri-pyridyl-s-Triazine and Phenyl-2pyridyl ketoxime. $2^{\text {nd }}$ Ed., G. F. Smith Chemical Co., Columbus, Ohio. $5-63$.

8. Diehl, H., G. F. Smith, A. A. Schilt and L. McBride, 1972. The Copper Reagents: Cuproine, Neocuproine, Bathocuproine. $2^{\text {nd }}$ Ed., G. F. Smith Chemical Co., Columbus, Ohio. 5-39.

9. Schilt, A. A., 1966. Some New Chromogens for Iron, Cobalt, and Copper Substituted Hydrazidines and 1,2,4-Triazines Containing the Ferroin Group. Talanta, 13, 895-902.
10. Schilt, A. A., 1969. Analytical Applications of 1,10Phenanthroline and Related Compounds. 32, Pergamon, New York. $56-78$.

11. Islam, M. A. and W. I Stephen, 1993. 3,5,6 Trisubstituted 1,2,4-Triazines as Analytical Reagents, Part I. Compounds Containing the Ferroin Functional Group or Iron( II)-Methine Chromophore. Anal. Chim. Acta, 274, 335-346.

12. Islam, M. A. and W. I Stephen, 1992. Evaluation of Some asTriazines and Re-evaluation of PDT and Ferrozine as Reagents for Spectrophotometric Determination of Ruthenium. Talanta, 39(11), 1429-35.

13. Ahmed, M. J. and U. K. Roy, 2009. A Simple Spectrophotometric Method for the Determination of Iron(II) in Aqueous Solutions. Turk. J. Chem, 33, 709-726.

14. Kiran, K. 2012, Spectrophotometric Determination of Iron in Water Samples Using 3-Hydroxy Benzyl Amino Benzoic acid. International Journal of Environmental Sciences, 3(1), 201-218.

15. Rajbhandari, A. and T. Subedi, 2013. Spectrophotometric Determination of Total Iron in Rice and Maize Samples. Scientific World, 11(11), 101 - 104.

16. Ahmed, M. J., M. T. Islam, M. J. Hossain and M. F. Islam, 2015. A Simple Spectrophotometric Method for the Trace Determination of Iron in Some Real, Environmental, Biological, Food, Pharmaceutical and Soil Samples Using 2aminophenol. American Chemical Science Journal, 7(4), 236-253.

17. Furniss, B. S., A. J. Hannaford, P. W. G. Smith and A. R. Tatchell, 1978. Vogel's Text Book of Practical Organic Chemistry. $4^{\text {th }}$ Ed. $1043-1045$. 
